This document is the accepted manuscript version of the following article:

Wilke, M., \& Casati, N. (2018). Insight into the mechanochemical synthesis and structural evolution of hybrid organic-inorganic guanidinium lead(II) iodides. Chemistry: A European Journal, 24(67), 17701-17711.

https://doi.org/10.1002/chem.201804066

\title{
Insight in the mechanochemical synthesis and structural evolution of hybrid organic-inorganic guanidinium lead(II) iodides
}

\author{
Manuel Wilke a and Nicola Casati*a \\ ${ }^{a}$ Laboratory for Synchrotron radiation - Condensed Matter, Paul Scherrer Institute, 5232 \\ Villigen PSI, Switzerland, nicola.casati@psi.ch, +41-56-310-5346
}

\begin{abstract}
We present the in situ investigations of the mechanochemical synthesis of four hybrid organic-inorganic lead(II) iodides of formula $\left(\mathrm{C}\left(\mathrm{NH}_{2}\right)_{3}\right)_{n} \mathrm{PbI}_{2+n}(\mathrm{n}=\mathbf{1}, \mathbf{2}, \mathbf{3}$, and 4). Synchrotron X-ray diffraction data show that the four guanidinium lead(II) iodides easily convert into each other. While the end product is dictated by the initial stoichiometry, we found complex pathways with different behaviors of the compounds regarding nucleation, growth and intermediate formation. We consider this to be linked to the respective structural features of the different compounds, especially the connectivity of the inorganic framework and the strength of ionic interactions. For the compounds $\mathbf{1}, \mathbf{3}$, and $\mathbf{4}$ high temperature studies were conducted, revealing new phases 1-II, 3-II, and 3-III. Unknown structures were solved from single crystal analysis and powder X-ray diffraction.
\end{abstract}

\section{Introduction}

To provoke chemical reactions by mechanical energy is named mechanochemistry, usually done in simple ball, planet or vibration mills. ${ }^{1}$ Mechanochemical synthesis is of increasing interest because of the gained high yields, high conversion rates, the easy handling, the little amount of used solvents and produced waste, and the good energy consumption, which make this method part of the green chemistry. ${ }^{2-4}$ Nowadays, plenty reactions are known: the formation of alloys, cocrystals, metal-organic coordination compounds, and even C-C coupling reactions. ${ }^{4-7}$ Mechanochemistry can provide products which are not accessible from solution based methods or very complex to obtain. ${ }^{8-10}$ During the last years different attempts were made to investigate the mechanisms behind mechanochemical reactions. Most promising are the in situ methods, using X-ray diffraction, Raman-spectroscopy, a combination of both, or IR camera temperature studies. ${ }^{11-14}$ Based on the studies over the last five years, it is known that mechanochemical reactions can have more complex pathways, including formation of intermediate products and transition to different phases. ${ }^{15-18}$

In 2015 Lewinski et al. described for the first time the mechanochemical synthesis of a 3D hybrid organic-inorganic perovskite, namely $\mathrm{CH}_{3} \mathrm{NH}_{3} \mathrm{PbI}_{3} .{ }^{19}$ Later on they could show how mechanochemistry can be used to incorporate other cations inside that structure. ${ }^{20,21}$ Recently, a study for the mechanochemical syntheses of inorganic perovskite-type lead(II) halides was published by Pal et al. ${ }^{22}$ They could easily create their compounds by grinding the respective metal halides together. The gained inorganic lead(II) halides could be transformed to other lead(II) halides by further grinding with another metal halide. Hybrid organic-inorganic perovskites have been of tremendous interest in research especially because of the methylammonium containing lead(II) halides, which are used for new generations of solar cells. ${ }^{23-26}$ The structure of organic-inorganic perovskites is by no mean restricted to $3 \mathrm{D}$ compounds. ${ }^{25}$ During the last years research focused also on 2D layered perovskites, since they are known to have interesting and unique photovoltaic properties. ${ }^{27-29}$ Formally, they are created by cutting the 3D perovskite structure 


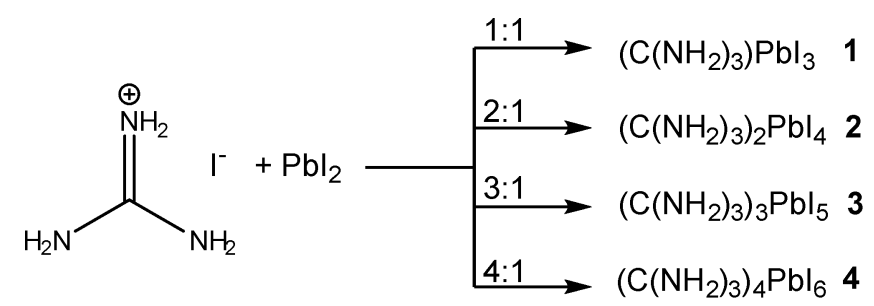

Figure 1: Schematic view of the conducted syntheses.

along a specific crystallographic plane and are therefore classified as $\langle 100\rangle-,\langle 110\rangle$-, and $\langle 111\rangle$-oriented perovskites. The straight corner-sharing perovskite connection can also lead to more exotic structures like 1D-chains, zigzag-motifs, or staircase forming layers. ${ }^{25,30,31}$ The octahedra in organic-inorganic lead(II) iodides can also be edge- and face-connected, which offers even more structural variety. ${ }^{32,33}$

Here we present the in situ investigation of the formation of a series of organic-inorganic hybrid materials from mechanochemical synthesis. The compounds are constructed by guanidinium-, lead(II)and iodide-ions, with the formula $\left(\mathrm{C}\left(\mathrm{NH}_{2}\right)_{3}\right)_{n} \mathrm{PbI}_{2+n}(\mathrm{n}=\mathbf{1}, \mathbf{2}, \mathbf{3}$, and $\mathbf{4}$, Figure 1). The inorganic structures change with an increasing number of included guanidinium iodide units from $1 \mathrm{D}$ doublechains (1) to a 2D $\langle 110\rangle$-perovskite structure $(\mathbf{2})$ to a $1 \mathrm{D}$ chain structure $(\mathbf{3})$ and finally to isolated lead(II) iodide octahedra (4). The structure of compound $\mathbf{2}$ and its two high temperature analogues were recently described in detail by Daub et al. ${ }^{34}$ The structure of $\mathbf{1}, \mathbf{3}$, and $\mathbf{4}$ were solved from single crystal and powder X-ray diffraction (PXRD) data. Temperature studies revealed that the compounds $\mathbf{1}$ and $\mathbf{3}$ undergo phase transitions. The respective structures were solved from PXRD data. The results from the in situ investigations of the mechanochemical syntheses show that the reactions undergo intermediate formations, phase transitions and reactions between the guanidinium lead(II) iodides.

\section{Experimental section}

\subsection{Chemicals}

The following chemicals were used without further purification: lead(II) iodide (99.99\%, TCI, Germany), guanidine hydroiodide ( $>97 \%$, TCI, Germany), hydroiodic acid $(57 \%,<1.5 \%$ hydrophosphorous acid as stabilizer, Sigma Aldrich, USA).

\subsection{Synthesis}

For all lab synthesis a vibration ball mill (Pulverisette 23, Fritsch GmbH, Germany) was used. In a standard synthesis $\mathrm{PbI}_{2}$ and guanidine hydroiodide were loaded in a $10 \mathrm{~mL}$ stainless steel jar with a total load of $500 \mathrm{mg}$ together with three stainless steel balls (diameter: $7 \mathrm{~mm}$, weight: $1.4 \mathrm{~g}$ ). The mixture was milled for $60 \mathrm{~min}$ at $40 \mathrm{~Hz}$.

For the in situ reaction a custom made jar and mill were used. They are described in detail elsewhere. ${ }^{35}$ The syntheses were conducted the same way as the lab syntheses. Additionally to the shaking a rotation movement was applied with a speed of 0.25 rotations per second.

Single crystals were grown from hydroiodic acid solutions containing $\mathrm{PbI}_{2}$ and guanidine hydroiodide. Mostly mixtures of more than one phase were obtained. The crystals for measurement were than chosen according to morphology.

\subsection{Analytical techniques}

All conducted X-ray diffraction experiments were performed at the X04SA Materials Science (MS) beamline at the Swiss Light Source (SLS), Paul Scherrer Institute. ${ }^{36}$ For all measurements a monochromatic beam was employed $(25.1 \mathrm{keV})$. The exact wavelength was refined using a calibrated $\mathrm{LaB}_{6}$ standard (SRM 660a, NIST, USA). 
The powdery products of the mechanochemical lab synthesis were filled in glass capillaries and measured in transmission geometry using a 1D Mythen II microstrip detector. For the temperature studies the setup was the same, except that a Cryostream 800 (Oxford Cryosystems, United Kingdom) was used to heat the sample. The capillaries were heated stepwise from $300 \mathrm{~K}$ to $500 \mathrm{~K}$ with a measurement at every $10 \mathrm{~K}$ step. Compound $\mathbf{1}$ was additionally heated up to $570 \mathrm{~K}$ using a gas blower (Cyberstar, France).

Single crystals were investigated using omega-scan method and a 2D hybrid pixel detector, namely Pilatus 6M.

The setup used for the in situ measurements was described in detail elsewhere. ${ }^{35}$ It allows the timeresolved investigation of mechanochemical reactions, delivering high-resolved PXRD data with low backgrounds and a good signal-to-noise ratio. The gained images were calibrated using the Dioptas program ${ }^{37}$ and integrated using the Bubble software. ${ }^{38} \mathrm{~A}$ single measurement took $20 \mathrm{~s}$. For the 2D-plots the patterns were background corrected with a scaled image of an empty jar. For a full profile refinement of the patterns three succeeding images were merged. The used $2 \theta$ range was limited from $1.7-7^{\circ}$.

\subsection{Structure solution and refinement}

The crystal structures of $\mathbf{1}$ and $\mathbf{3}$ were solved from single crystal data using CrysAlis Pro (version 171.39.46, Rigaku Oxford Diffraction, United Kingdom), Olex2 (version 1.2, OlexSys Ltd) and SHELXL, ${ }^{39}$ implemented in Olex2. The position of the inorganic moiety in the structure of $\mathbf{4}$ was determined from single crystal data. The results were used for the simulating annealing routine, conducted in Topas (version 5, Bruker AXS, Germany) using PXRD data. The guanidinium-ions were given as Rigid Bodies. All used phases for in situ data treatment were refined once against a pattern containing mainly the desired phase and then fixed. The refinements were then conducted automatically using Topas.

3 undergoes two phase transitions at $320 \mathrm{~K}$ and $450 \mathrm{~K}$. The symmetry changes from monoclinic over orthorhombic to tetragonal. The high temperature structures were solved from PXRD data using Expo2014 ${ }^{40}$ and the simulated annealing routine implemented in Topas. The same procedure was used for the structure solution of the hexagonal high temperature phase of $\mathbf{1}$.

PXRD data of the products of the mechanochemical lab syntheses were used for Rietveld refinements to proof the nature of the compounds.

CCDC-1860733-CCDC-1860738 contain the supplementary crystallographic data for 1, 1-II, 3, 3-II, 3-III, and 4. These data can be obtained free of charge from the Cambridge Crystallographic Data Centre via www.ccdc.cam.ac.uk/structures.

\section{Results and discussion}

\subsection{Syntheses and structure}

The respective crystal data and refinement parameter for all compounds are listed in Table 1. The final Rietveld refinements for the mechanochemical products and high temperature phases are shown in Figure S1-S4. Selected bond length and angles for the new structures are provided in Table S1-S6.

Lab-milling reactions for $\mathbf{1}, \mathbf{2}$, and $\mathbf{4}$ always give the stoichiometric product. We note that a $\mathrm{PbI}_{2}$ and guanidine hydroiodide ratio of 1:3 has at times resulted not in compound $\mathbf{3}$, but in an equal mixture of compound $\mathbf{2}$ and $\mathbf{4}$, which also fulfills the given stoichiometry. First attempts were done to shed light on that issue. The kinetics of formation of the different compounds is discussed below in the section about the in situ studies.

The structure of $\mathbf{1}$ is depicted in Figure 2. Its existence was reported earlier, but only the space group and a short description of the inorganic framework were given, without further data. ${ }^{41}$ Nevertheless, their description is in accordance with our findings. The structure consists of slightly distorted $\mathrm{PbI}_{6}$-octahedra $\left(\mathrm{d}_{\mathrm{Pb}-\mathrm{I}}=3.0671(6)-3.4305(6) \AA, L_{\mathrm{I}-\mathrm{Pb}-\mathrm{I}}=85.796(1)-93.639(1)^{\circ}\right)$. Every octahedra is connected with four other octahedra through an edge, respectively. As a result double chains along the b-axis are formed. The guanidinium-ion is located in the interchain space, connecting three chains by weak hydrogen bonds 


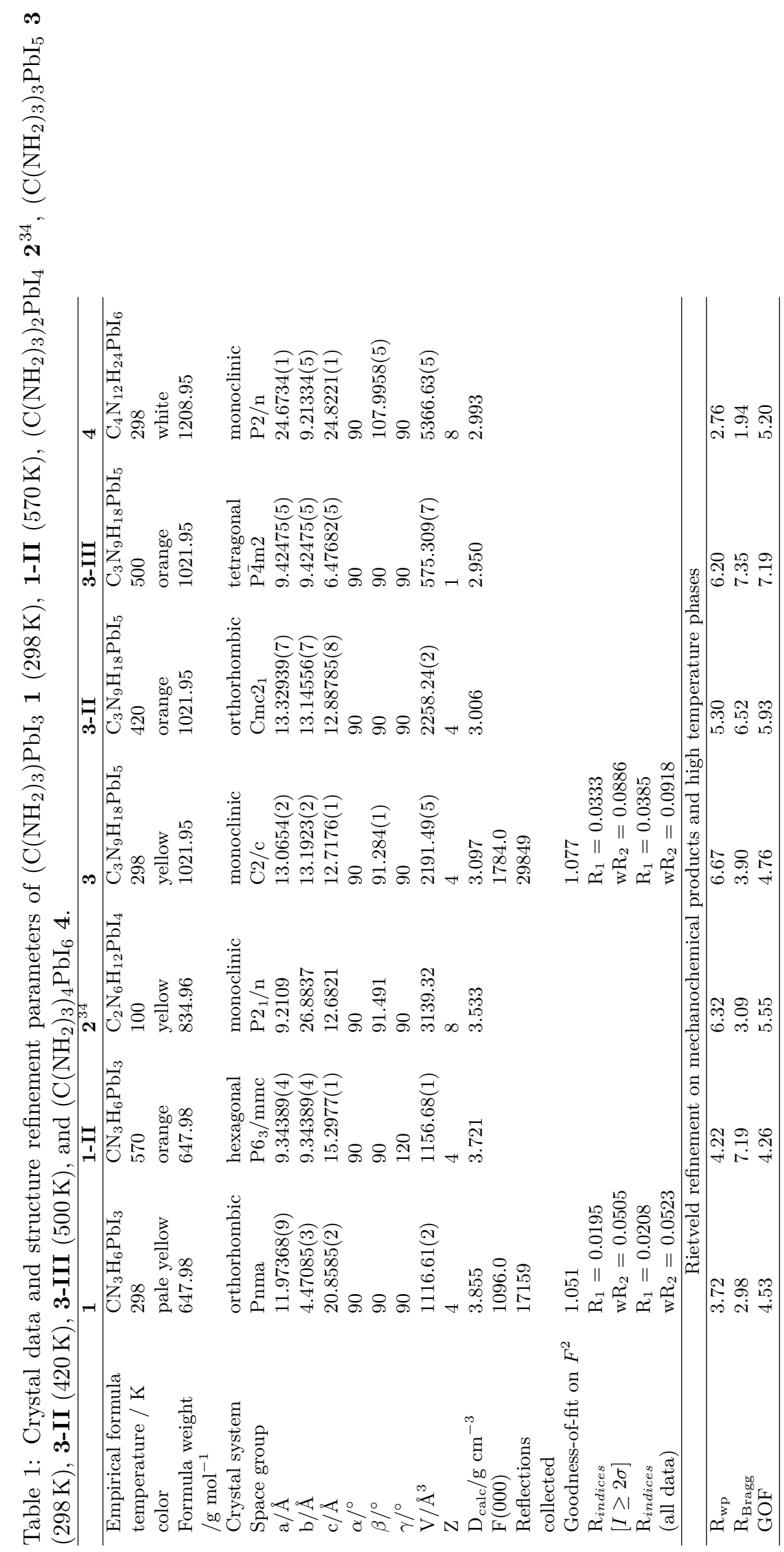


$\left(\mathrm{d}_{\mathrm{N} 1-\mathrm{I} 2}=3.613(6) \AA, \mathrm{d}_{\mathrm{N} 2-\mathrm{I} 1}=3.695(6) \AA, \mathrm{d}_{\mathrm{N} 3-\mathrm{I} 1}=3.764(7) \AA\right)$. The double chains are tilted with respect to the unit cell and ordered in an herringbone pattern.

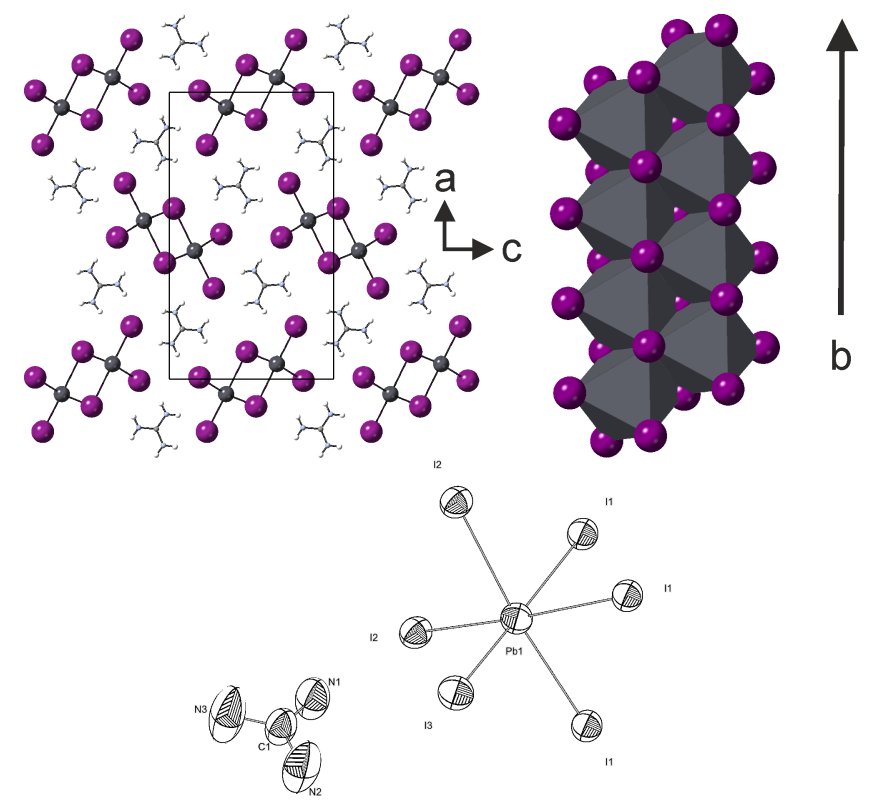

Figure 2: Structure of $\left(\mathrm{C}\left(\mathrm{NH}_{2}\right)_{3}\right) \mathrm{PbI}_{3}$ 1. Top left Unit cell with guanidinium-ions and inorganic chains build by edge-sharing $\mathrm{PbI}_{6}$-octahedra, shown along the b-axis. Top right Connection of the $\mathrm{PbI}_{6^{-}}$ octahedra within the chain. Bottom $\mathrm{PbI}_{6}$-octahedra and guanidinium-ion, atoms are shown as ellipsoids at the $50 \%$ level. Black: led, purple: iodine, lilac: nitrogen, gray: carbon, white: hydrogen.

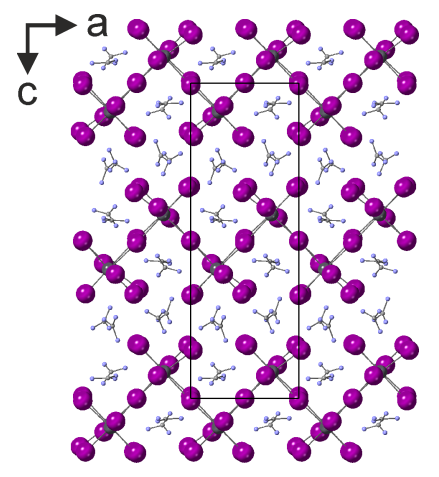

Figure 3: Structure of $\left(\mathrm{C}\left(\mathrm{NH}_{2}\right)_{3}\right)_{2} \mathrm{PbI}_{4} \mathbf{2}$ shown along the b-axis. ${ }^{34}$

The structure of $\mathbf{2}$ is described in detail in literature. ${ }^{34} \mathbf{2}$ forms a layered $\langle 110\rangle$-oriented perovskite structure (Figure 3).

The structure of $\mathbf{3}$ is shown in Figure 4. The $\mathrm{Pb}^{2+}$-ion is coordinated by six $\mathrm{I}^{-}$-ions in a slightly distorted octahedron $\left(\mathrm{d}_{\mathrm{Pb}-\mathrm{I}}=3.2113(5)-3.2498(1) \AA, L_{\mathrm{I}-\mathrm{Pb}-\mathrm{I}}=86.17(1)-93.83(1)^{\circ}\right)$. The octahedra are connected via two opposite corners forming a one dimensional perovskite, resulting in zigzag chains along the c-axis $\left(\angle_{\mathrm{Pb}-\mathrm{I}-\mathrm{Pb}}=156.11(2)^{\circ}\right)$. Additionally, the octahedra are tilted along the chain, the torsion angle of two nearby octahedra is $6.27(2)^{\circ}$. The guanidinium-ions are located between the chains. The position of one guanidinium-ion is disordered. With an equal occupancy the $\mathrm{N}$-atoms have a second position, rotated $180^{\circ}$ around an axes through $\mathrm{C} 2$ along to the molecule plane. The guanidinium-ions form a manifold network of hydrogen bonds to neighbored chains, with the shortest distance of 3.46(2) $\AA$ between N5 and I2. Along the a- and the b-axis the chains are ordered in an alternating abab manner.

The structure of $\mathbf{4}$ is shown in Figure 5. It consists of two types of isolated $\mathrm{PbI}_{6}$-octahedra. Both are slightly distorted $\left(\mathrm{d}_{\mathrm{Pb} 1-\mathrm{I}}=3.177(6)-3.317(6) \AA, L_{\mathrm{I}-\mathrm{Pb} 1-\mathrm{I}}=86.2(1)-95.3(2)^{\circ} ; \mathrm{d}_{\mathrm{Pb} 2-\mathrm{I}}=3.206(6)\right.$ 


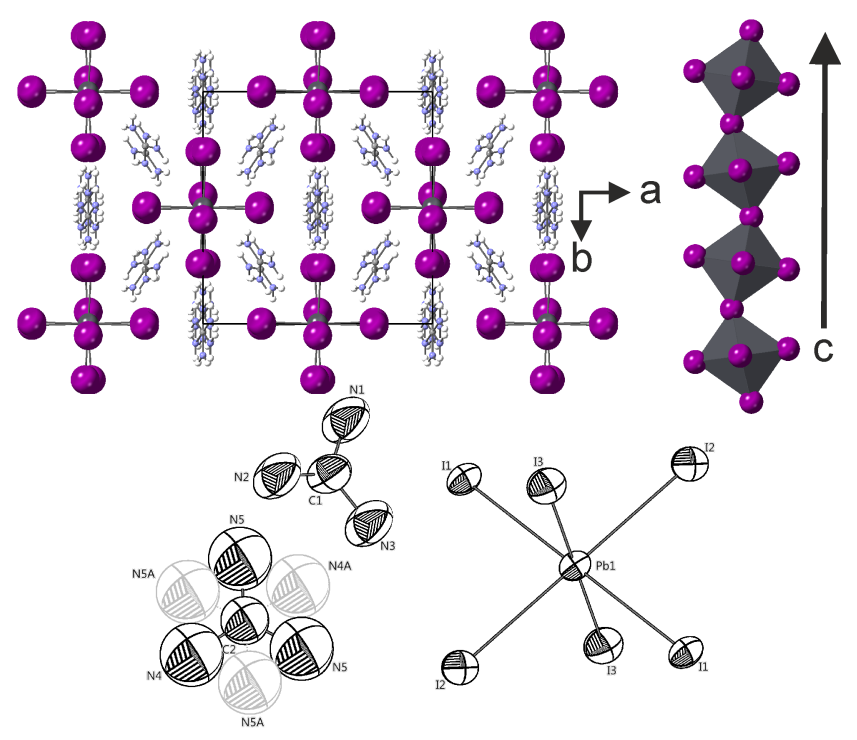

Figure 4: Structure of $\left(\mathrm{C}\left(\mathrm{NH}_{2}\right)_{3}\right)_{3} \mathrm{PbI}_{5}$ 3. Top left Unit cell with guanidinium-ions and inorganic chains build by $\mathrm{PbI}_{6}$-octahedra, shown along the c-axis. Top right Connection of the $\mathrm{PbI}_{6}$-octahedra within the chain. Bottom $\mathrm{PbI}_{6}$-octahedra and guanidinium-ions, atoms are shown as ellipsoids at the $50 \%$ level. Black: led, purple: iodine, lilac: nitrogen, gray: carbon, white: hydrogen.

- 3.288(6) $\left.\AA, \angle_{\mathrm{I}-\mathrm{Pb} 2-\mathrm{I}}=83.2(1)-96.2(2)^{\circ}\right)$. The octahedra are arranged in a layer-like manner. The guanidinium-ions are connecting the $\mathrm{PbI}_{6}$-octahedra by hydrogen-bonds, with N-I-distances down to $3.13(5) \AA(\mathrm{N} 17-\mathrm{I} 8)$.

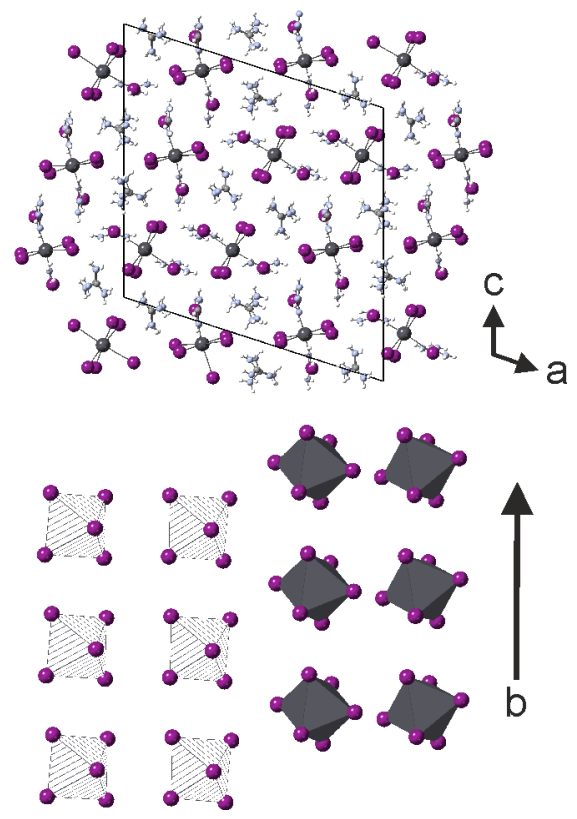

Figure 5: Structure of $\left(\mathrm{C}\left(\mathrm{NH}_{2}\right)_{3}\right)_{4} \mathrm{PbI}_{6}$ 4. Top Unit cell with guanidinium-ions and isolated $\mathrm{PbI}_{6^{-}}$ octahedra, shown along the b-axis. Bottom Arrangement of the two types of $\mathrm{PbI}_{6}$-octahedra; black octahedra: $\mathrm{Pb} 1$, striped octahedra $\mathrm{Pb}$. Black: led, purple: iodine, lilac: nitrogen, gray: carbon, white: hydrogen. 


\subsection{High temperature studies}

Heating 1 leads to a phase change starting at $430 \mathrm{~K}$. This is in accordance with DTA measurements, published by Szafranski in $1997 .{ }^{42}$ He proposed a first order phase transition. Our results show that at this temperature the new phase consists of numerous broad peaks. Only at higher temperatures (up to $570 \mathrm{~K}$ ) the structures is getting well ordered, providing less and sharper reflections. The former orthorhombic symmetry changes to hexagonal. The edge-connected, double chain forming octahedra are now faceand corner-connected, resulting in a three dimensional inorganic framework with a honeycomb-structure (1-II, Figure 6). The pores of this framework are filled with the guanidinium-ions. The structure can be described as an $\langle 111\rangle$-oriented layered perovskite, where the layers are connected by face-sharing $\mathrm{PbI}_{6}{ }^{-}$ octahedra (Figure 6, right). The layer lies within the a-b-plane. The transition is reversible and 1-II reconvert to $\mathbf{1}$ when the temperature is decreased (Figure S5). The structure of 1-II is similar to the previously reported structure of $\left(\mathrm{CH}_{3} \mathrm{C}\left(\mathrm{NH}_{2}\right)_{2}\right) \mathrm{SnI}_{3} \cdot{ }^{43}$ Here the anion is acetamidinium and the metal is tin(II). Because of the missing threefold rotation axis within acetamidinium-ion the symmetry is reduced to $\mathrm{P} 6{ }_{3} \mathrm{mc}$. At variance to our structure this one is stable at room temperature. Since acetamidinium and guanidinium have similar steric characteristics, they are able to template the same type of inorganic framework. Nevertheless, the methyl group of acetamidinium will interact much less with iodine than the amine groups. With increasing temperature the interplay between the amine and the iodine will become less important. We consider that to be the reason why $\left(\mathrm{CH}_{3} \mathrm{C}\left(\mathrm{NH}_{2}\right)_{2}\right) \mathrm{SnI}_{3}$ is stable at room temperature and 1-II only at high temperatures. The guanidinium analog with tin(II) was described in the same publication. It has a 3D hexagonal structure as well, but here the $\langle 111\rangle$ oriented layers are only to one side face connected and edge and corner connected to the other side, resulting in a shift of the layers, which prevents the existence of channels. The compound is stable at room temperature.
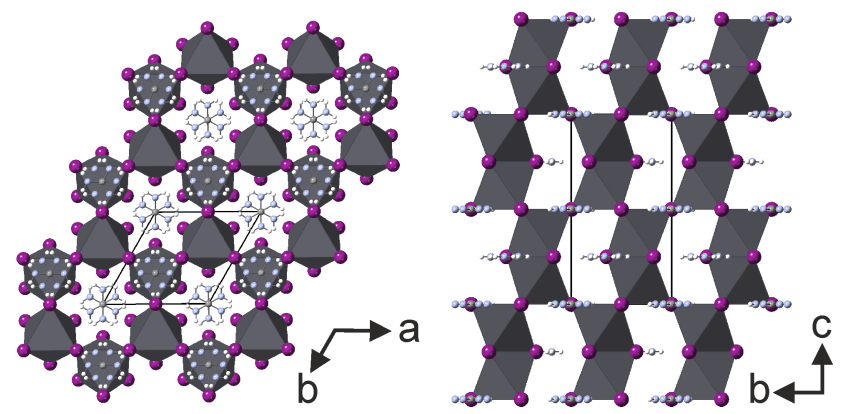

Figure 6: Structure of $\left(\mathrm{C}\left(\mathrm{NH}_{2}\right)_{3}\right) \mathrm{PbI}_{3}$ 1-II at $570 \mathrm{~K}$. Unit cell with an inorganic framework build by $\mathrm{PbI}_{6}$-octahedra and guanidinium-ions in the pores, left shown along the c-axis and right shown along the a-axis. Black: led, purple: iodine, lilac: nitrogen, gray: carbon, white: hydrogen.

Daub et al. found two phase transition for $\mathbf{2}$ from measurements at different temperatures. ${ }^{34}$ The changes are mostly based on a progressively more symmetric arrangement of the inorganic part. The symmetry of the cell does change from monoclinic to orthorhombic and for the high temperature phase the volume of the cell is halved.

A similar behavior could be found for $\mathbf{3}$. The monoclinic structure does change to an orthorhombic one, starting at $320 \mathrm{~K}$. This change is based on a better ordering of the inorganic chain (Figure 7). The zigzag form is the same, but the octahedra are not tilted anymore along the chain. The second phase change starts at $450 \mathrm{~K}$. The angles of the $\mathrm{PbI}_{6}$-octahedra are not distorted anymore and the former zigzag chain is now perfectly linear (Figure 8). The symmetry does change to tetragonal and the cell volume is quartered. The positions of the guanidinium-ions are distorted. All described changes are reversible, by cooling down the sample upon room temperature the previous phase is obtained (Figure S6).

At $370 \mathrm{~K} 4$ undergoes a process finally leading to its decomposition into 3-II and the monoclinic high-temperature phase of guanidine hydroiodide. During this process reflections of an unknown phase appear at the very beginning and vanish with time (Figure S7). These changes are irreversible. The recovered sample shows only reflection of compound 3 (Figure S8) and guanidine hydroiodide. This 


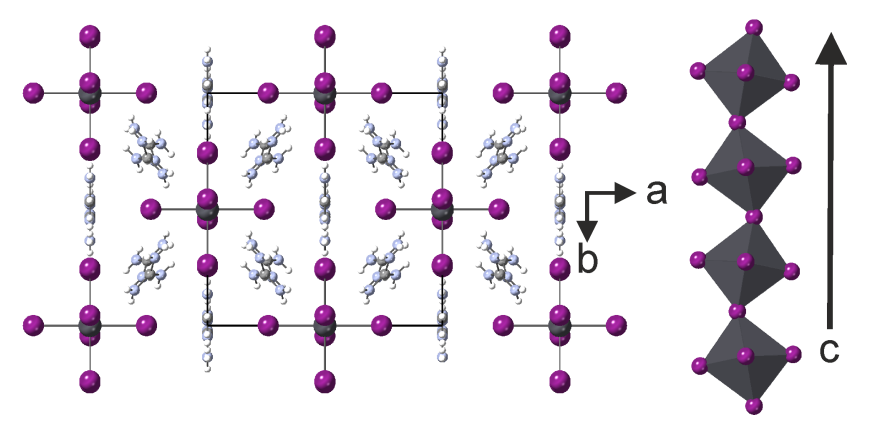

Figure 7: Structure of $\left(\mathrm{C}\left(\mathrm{NH}_{2}\right)_{3}\right)_{3} \mathrm{PbI}_{5}$ 3-II at $420 \mathrm{~K}$. Left Unit cell with guanidinium-ions and inorganic chains build by $\mathrm{PbI}_{6}$-octahedra, shown along the c-axis. Right Connection of the $\mathrm{PbI}_{6}$-octahedra within the chain. Black: led, purple: iodine, lilac: nitrogen, gray: carbon, white: hydrogen.

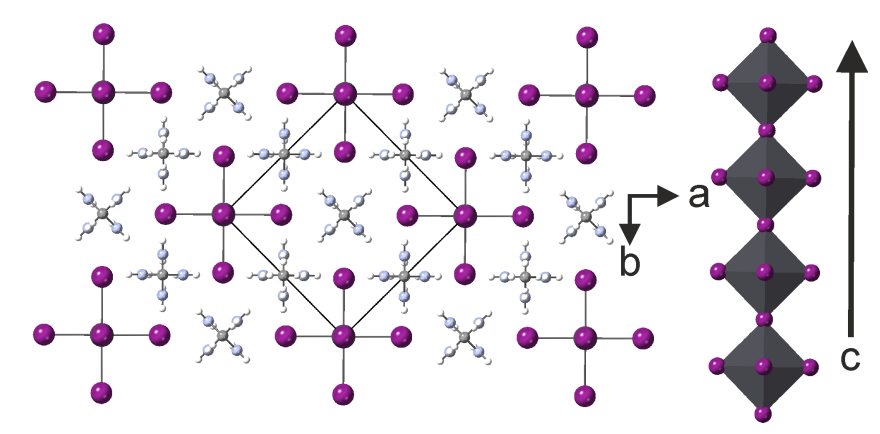

Figure 8: Structure of $\left(\mathrm{C}\left(\mathrm{NH}_{2}\right)_{3}\right)_{3} \mathrm{PbI}_{5}$ 3-III at $500 \mathrm{~K}$. Left Unit cell with guanidinium-ions and inorganic chains build by $\mathrm{PbI}_{6}$-octahedra, shown along the c-axis. Right Connection of the $\mathrm{PbI}_{6}$-octahedra within the chain. Black: led, purple: iodine, lilac: nitrogen, gray: carbon, white: hydrogen.

conversion from 4 to 3 at medium temperature hints at the simple interconversion between the different compounds, as later shown in the in situ section.

In all structures the inorganic ions are forming $\mathrm{PbI}_{6}$-octahedra. A higher amount of iodine lowers the connections between octahedra. $\left(\mathrm{C}\left(\mathrm{NH}_{2}\right)_{3}\right) \mathrm{PbI}_{3}$ forms edge connected octahedra at room temperature (1) and face as well as corner connected octahedra at higher temperatures (1-II). The compounds $\mathbf{2}$ and $\mathbf{3}$ consist of corner-sharing octahedra at all temperatures and finally $\mathbf{4}$ consists of isolated octahedra. Based on its composition, $\mathbf{1}$ could also form the classic 3D perovskite, consisting of corner-sharing octahedra like the respective compound containing methylammonium. ${ }^{44}$ Calculations of the tolerance factor, using the effective ionic radii of guanidinium, lead(II) and iodine, show that the guanidinium-ion is too space demanding for this structure-type. ${ }^{45}$ In all compounds, the guanidinium-ions are located between the inorganic moieties, templating and stabilizing the structure. The N-I-distances for the compounds at room-temperature are getting smaller in the order $\mathbf{1}>\mathbf{2}>\mathbf{3}>\mathbf{4}$. This can be interpreted as stemming from two effects: on one hand a less expanded inorganic framework is able to adapt better to an optimal configuration for intermolecular contacts. On the other, the increased charge on the octahedra reinforces and shortens the hydrogen bonds.

\subsection{In situ studies}

The mechanochemical syntheses of compounds 1-4 were studied in situ. The results show that the four guanidinium lead(II) iodides easily convert into each other. Every synthesis contains intermediate phases. Additionally, the high temperature phase of the starting material guanidine hydroiodide is observed during three of the syntheses. Guanidine hydroiodide consists of a hexagonal crystal structure at room temperature where the positions of the $\mathrm{I}^{-}$-ions are disordered. ${ }^{46}$ At $360 \mathrm{~K}$ a phase transition takes place, the $\mathrm{I}^{-}$-ions are not distorted anymore and the symmetry changes to monoclinic. For the 
description of $\mathbf{2}$ in the refinement the best results were gained using the structure given by Daub et al. for temperatures between $307 \mathrm{~K}$ and $356 \mathrm{~K}$.

The 2D plot for the in situ investigation of the synthesis of $\mathbf{1}$ is depicted in Figure 9a. The distribution of the crystalline phases during the reaction is shown in Figure 10a. At the beginning only reflections of the starting materials can be detected $\left(\mathrm{PbI}_{2}: 4.1^{\circ}, 8.2^{\circ}\right.$; guanidine hydroiodide: $\left.4.6^{\circ}, 5.1^{\circ}, 6.5^{\circ}, 7.9^{\circ}\right)$. The ratio is consistent to the used stoichiometry. The amount of guanidine hydroiodide drops then much faster than the one of lead(II) iodide. After one minute weak reflections for compound 1 (e.g. $2.7^{\circ}, 3.6^{\circ}$, $\left.7.2^{\circ}\right), \mathbf{2}\left(3.7^{\circ}, 4.4^{\circ}\right)$, and $\mathbf{3}\left(\mathrm{e} . \mathrm{g} .3 .1^{\circ}\right)$ can be detected. The amount of $\mathbf{3}$ increases the fastest but reaches only about $20 \%$ at its maximum. 2 grows slower and reaches after $10 \mathrm{~min}$ its maximum at about $25 \%$. The intensity of the reflections of $\mathbf{1}$ keep increasing until reaction completion. Reflections of guanidine hydroiodide cannot be observed after circa $7 \mathrm{~min}$, while those of lead(II) iodide after circa $28 \mathrm{~min}$; by this time the reaction is completed.

Figure $9 \mathrm{~b}$ shows the 2D-Plot of the in situ investigation of the synthesis of $\mathbf{2}$ and Figure 10b the change of the phase distribution with time. As in the synthesis of $\mathbf{1}$ at the beginning only reflections for the two starting materials can be detected. The values met the given stoichiometry. Within the first two minutes reflections of $\mathbf{1}$ can be detected (most intense at $2.7^{\circ}$ ). Shortly later reflections of 3 (most intense at $3.1^{\circ}$ ) occur. Additionally another intermediate can be detected. Weak reflections at $5.1^{\circ}$ and $5.2^{\circ}$ show that the monoclinic high temperature phase of guanidine hydroiodide is formed as intermediate. After circa $3 \mathrm{~min}$ reflections of the final product $\mathbf{2}$ can be detected. The development of the three intermediates differs in speed, amount and life time. The ratio of $\mathbf{3}$ raises very fast and reaches over $50 \%$ after circa 9 min. It stays until minute 22.1 stays probably slightly longer, but it grows much slower and reaches only a maximum amount of about $10 \%$. The monoclinic high temperature phase of guanidine hydroiodide grows as fast as $\mathbf{3}$. But it reaches its maximum already after $5 \mathrm{~min}$ and after $9 \mathrm{~min}$ its reflections are already vanished. The amount of the product grows slowly at the beginning. But when 3 reaches its maximum and, at the same time, no guanidine hydroiodide can be detected anymore, the speed increases. The reflections of lead(II) iodide vanish after circa $22 \mathrm{~min}$ and around that time the reaction seems to be over.

The 2D plot of the in situ investigation of the synthesis of $\mathbf{3}$ is shown in Figure 9c, while the respective time-resolved data for the ratios of the phases are plotted in Figure 10c. At the beginning only peaks that can be assigned to the starting materials can be detected and the determined ratio is consistent to the used stoichiometry. After about $2 \mathrm{~min}$ the monoclinic high temperature phase of guanidine hydroiodide is formed again as intermediate and its amount increases fast. Shortly later, reflections which can be assigned to $\mathbf{3}$ and, even later, to $\mathbf{1}$ and $\mathbf{2}$ appear. The ratio of the monoclinic high temperature phase of guanidine hydroiodide increase the fastest. It reaches a maximum of circa $30 \%$ after $10 \mathrm{~min}$. Compound $\mathbf{3}$ grows slower but its production accelerates, until at around 15 min reflections of $\mathbf{4}$ appear. Now this phase is growing very fast while the growth of phase $\mathbf{3}$ is decelerated. It even reaches a small plateau after 20 min. Than the ratio of $\mathbf{4}$ is at its maximum (20\%) and at the same time the reflections for any guanidine hydroiodide have vanished. The amount of $\mathbf{3}$ is now increasing again. After about $35 \mathrm{~min}$ all reflections belonging to the starting materials or any intermediate are vanished. The ratios of the intermediates $\mathbf{1}$ and $\mathbf{2}$ do not reach values higher than $6 \%$ and $3 \%$ during the reaction, respectively.

The 2D-plot of the in situ investigation of the synthesis of $\mathbf{4}$ is depicted in Figure $9 \mathrm{~d}$ and the corresponding graph with the time-resolved distribution data in Figure 10d. The amount of the starting materials at the beginning is consistent with the given stoichiometry. After 2 min reflections of the monoclinic high-temperature guanidine hydroiodide phase, of $\mathbf{3}$, and of $\mathbf{1}$ can be detected. Shortly later also the formation of $\mathbf{2}$ is observed. The ratios of the high-temperature guanidine hydroiodide phase and $\mathbf{3}$ are increasing rapidly, while the produced amount of $\mathbf{1}$ and $\mathbf{2}$ stays very small. The high-temperature guanidine hydroiodide phase instead reaches at the maximum about $20 \%$ after circa 9 min. The amount of 3 goes up to even $33 \%$ after circa $13 \mathrm{~min}$. The product instead can be detected for the first time only after $11 \mathrm{~min}$ but than its amount increases very fast. Reflections of lead(II)-iodide are vanished after circa 17 min while the one for guanidine hydroiodide stay until $31 \mathrm{~min}$. At that time also the reflections of the intermediates are vanished, the life time of the monoclinic high-temperature guanidine hydroiodide 
a) $\left(\mathrm{C}\left(\mathrm{NH}_{2}\right)_{3}\right) \mathrm{Pbl}_{3} 1$
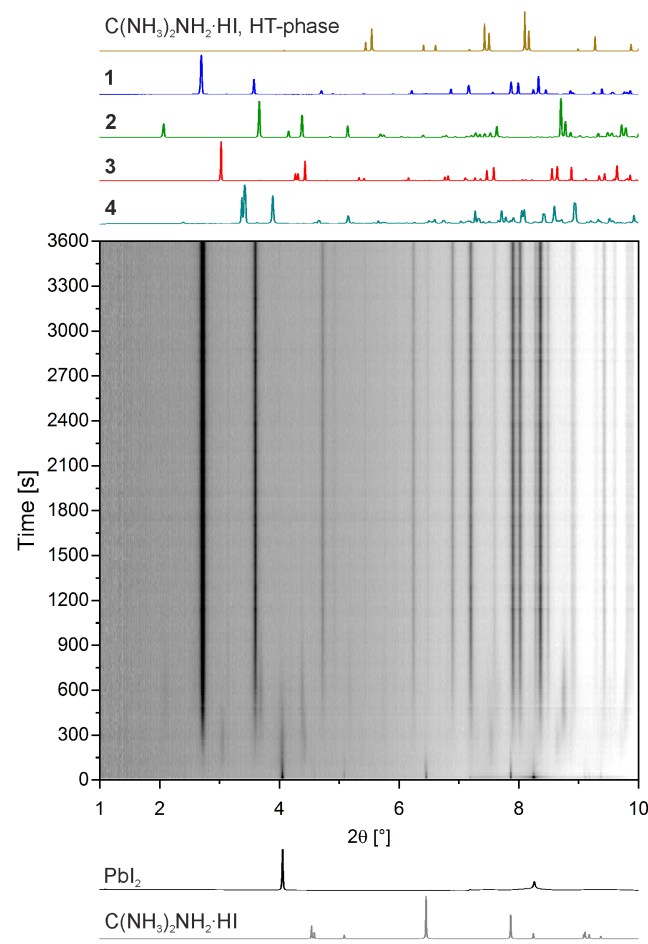

c) $\left(\mathrm{C}\left(\mathrm{NH}_{2}\right)_{3}\right)_{3} \mathrm{Pbl}_{5} 3$

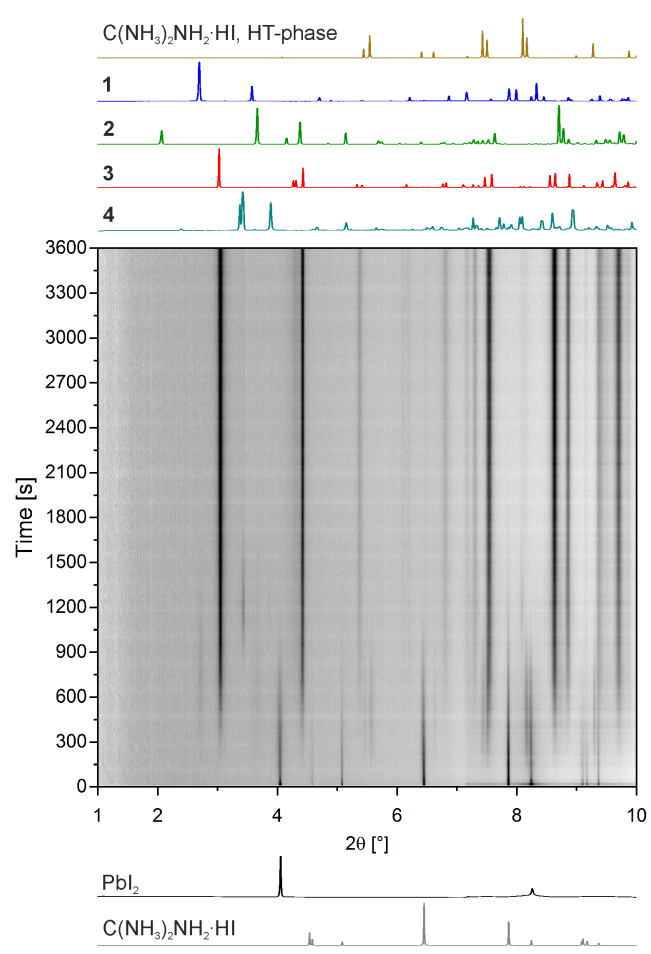

b) $\left(\mathrm{C}\left(\mathrm{NH}_{2}\right)_{3}\right)_{2} \mathrm{Pbl}_{4} 2$

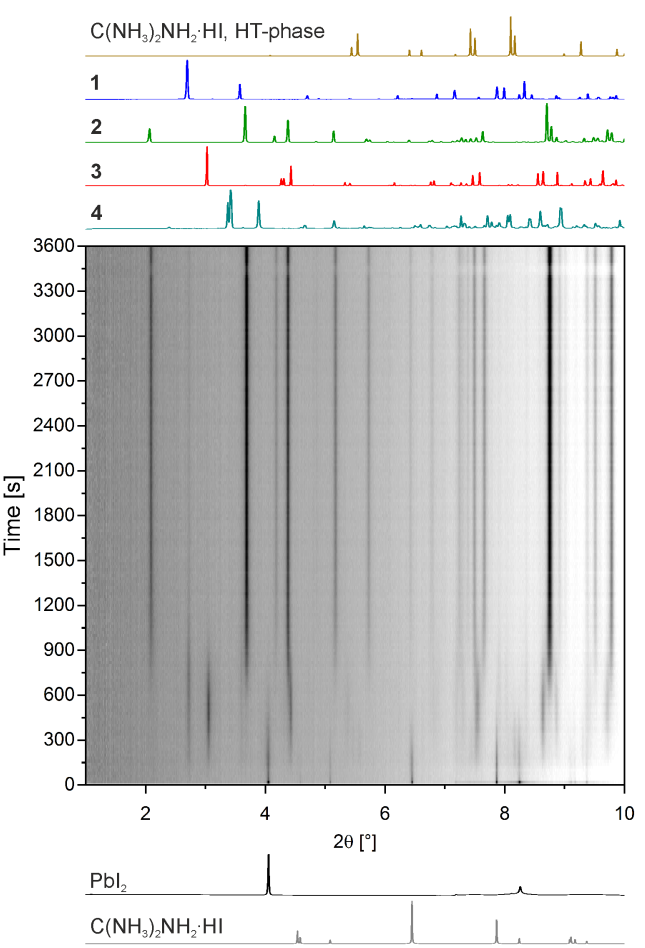

d) $\left(\mathrm{C}\left(\mathrm{NH}_{2}\right)_{3}\right)_{4} \mathrm{Pbl}_{6} 4$

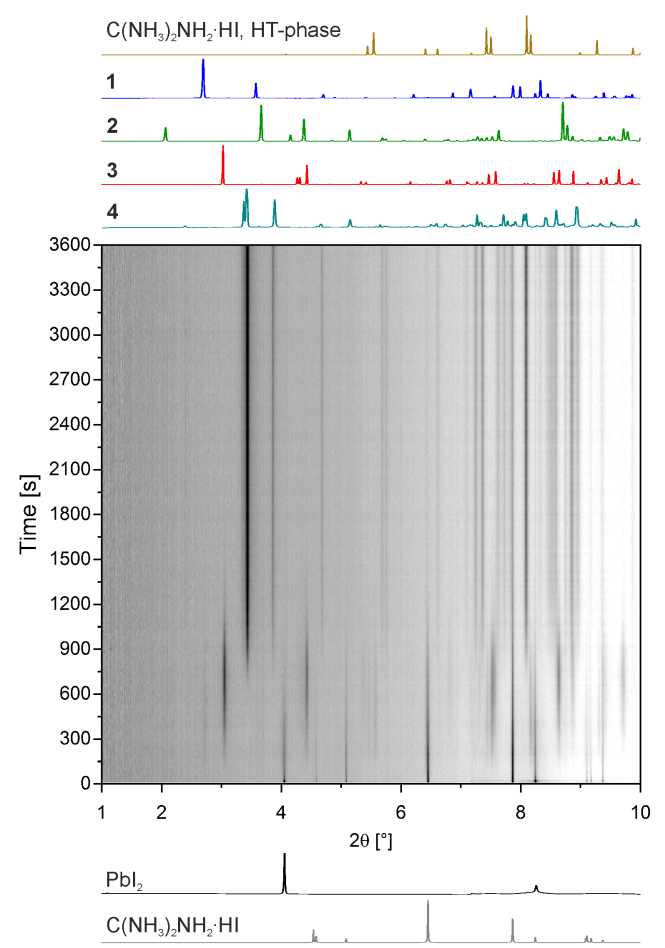

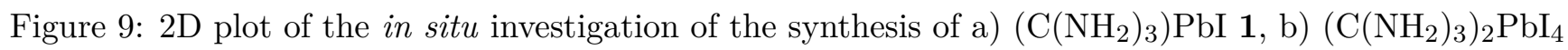
2, c) $\left(\mathrm{C}\left(\mathrm{NH}_{2}\right)_{3}\right)_{3} \mathrm{PbI}_{5}$ 3, and d) $\left(\mathrm{C}\left(\mathrm{NH}_{2}\right)_{3}\right)_{4} \mathrm{PbI}_{6}$ 4. The patterns for guanidine hydroiodide and for the monoclinic guanidine hydroiodide high-temperature phase are calculated from the structures given by Szafranski et al. ${ }^{46}$; pattern color: brown: high temperature phase of guanidine hydroiodide, blue: compound 1, green: compound 2, red: compound 3, turquoise: compound 4, black: lead(II) iodide, gray: guanidine hydroiodide. 
a) $\left(\mathrm{C}\left(\mathrm{NH}_{2}\right)_{3}\right) \mathrm{Pbl}_{3} 1$

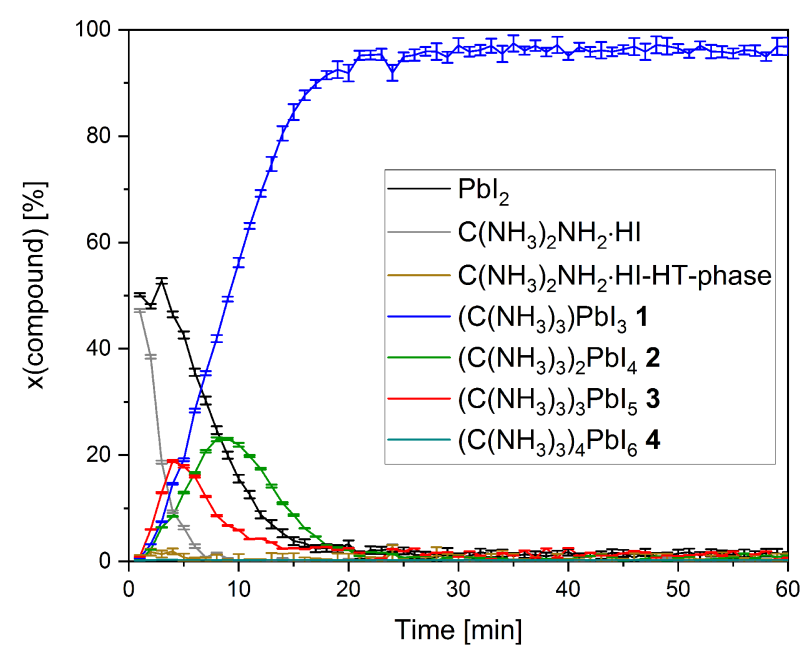

c) $\left(\mathrm{C}\left(\mathrm{NH}_{2}\right)_{3}\right)_{3} \mathrm{Pbl}_{5} 3$

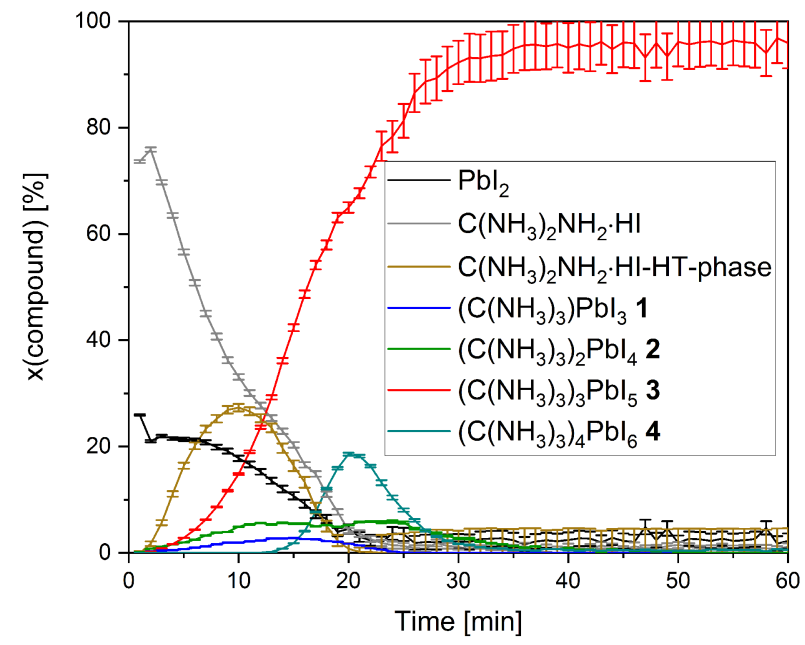

b) $\left(\mathrm{C}\left(\mathrm{NH}_{2}\right)_{3}\right)_{2} \mathrm{Pbl}_{4} 2$

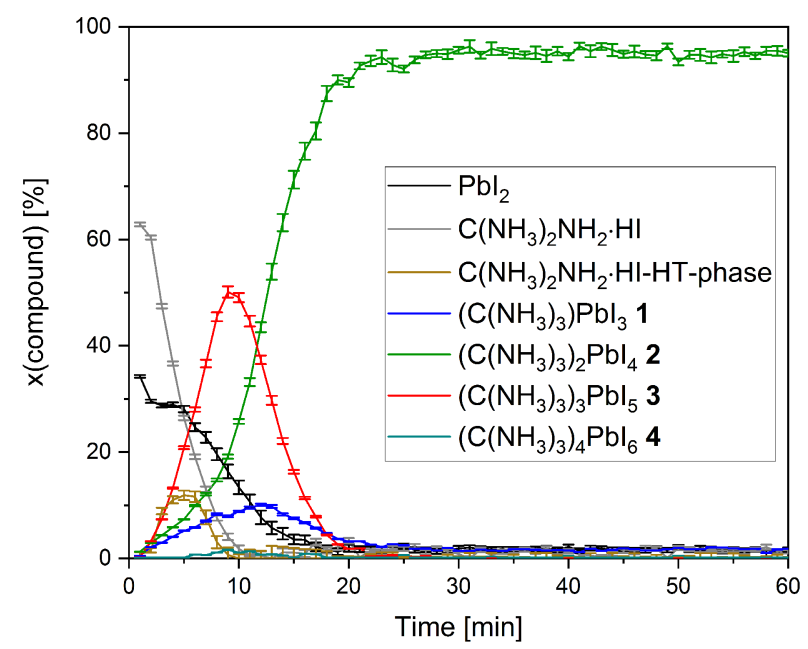

d) $\left(\mathrm{C}\left(\mathrm{NH}_{2}\right)_{3}\right)_{4} \mathrm{Pbl}_{6} 4$

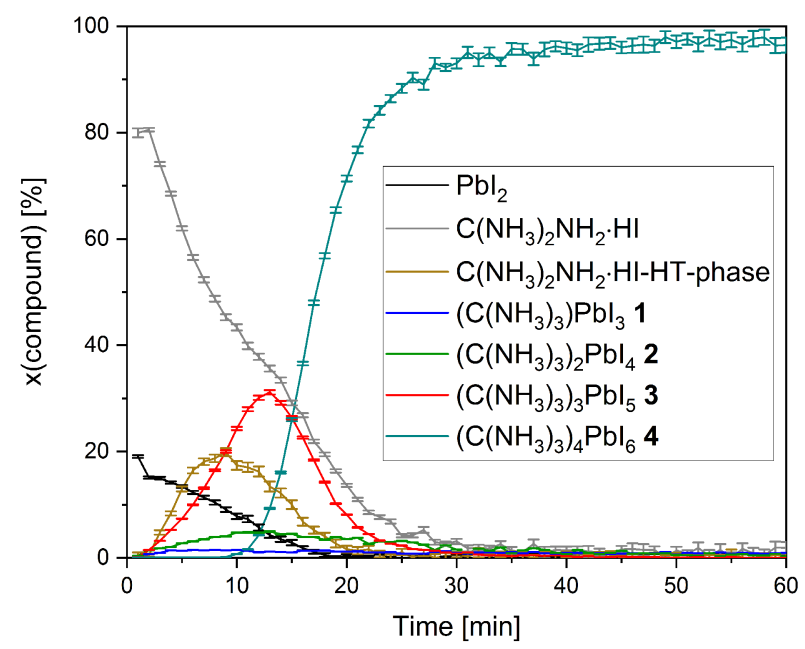

Figure 10: Time-resolved change of the amount of the given compounds for the in situ investigation of the synthesis of a) $\left(\mathrm{C}\left(\mathrm{NH}_{2}\right)_{3}\right) \mathrm{PbI} \mathbf{1}$, b) $\left(\mathrm{C}\left(\mathrm{NH}_{2}\right)_{3}\right)_{2} \mathrm{PbI}_{4} \mathbf{2}$, c) $\left(\mathrm{C}\left(\mathrm{NH}_{2}\right)_{3}\right)_{3} \mathrm{PbI}_{5} \mathbf{3}$, and d) $\left(\mathrm{C}\left(\mathrm{NH}_{2}\right)_{3}\right)_{4} \mathrm{PbI}_{6}$ 4. 
phase was meanwhile noticeably shorter than the lifetime of phase $\mathbf{2}$ and $\mathbf{3}$.

Since we investigate a dynamic, moving system the whole profile refinement is limited, meaning that amounts below 3-5\% for a compound cannot be fully trusted. Also the value for the calculated errors are likely to be underestimated. That said, the continuity of the developments proofs that the gained values are true in principle. Moreover, a careful check of the presence of compounds has been carried out manually: in the above description the presence of the different compounds is inferred based on this check.

Grinding reactive powders in a ball mill does not necessarily lead to a homogenous mixture. Additionally caking of the materials and different reaction spots within the jar may occur. ${ }^{47-49}$ This can cause problems for the in situ investigations, since only a small amount of the powder is in the pathway of the beam. The applied rotational movement for the in situ investigations leads to a better mixing of the solids, ${ }^{35}$ including a negligible tendency to cake at the top or bottom position of the jar. After no reaction the powder was strongly caked or disproportionately distributed in the jar, which is probably also based on the properties of the used and produced materials and the absence of liquids. To validate the reaction pathways, all shown results are based on duplicated studies. 2D plots of raw data for a second set of reactions are reported in Figure S9 for direct comparison; the data shown in Figure 9 and 10 come from a single experimental setup with improved background stability, given by synchronization of acquisition and rotation speed.

As mentioned before, for $\mathbf{2}$ the structure given by Daub et al. for temperatures between $307 \mathrm{~K}$ and $356 \mathrm{~K}$ was used. Also the formation of the monoclinic high-temperature guanidine hydroiodide phase can be observed, which is stable at temperatures above $360 \mathrm{~K}$. As shown in literature, very high temperatures for mechanochemical reactions in a comparable vibration ball mill (Pulverisette 23, Fritsch GmbH, Germany) during the milling process are unlikely. ${ }^{14,50}$ Instead of a steel jar a custom-made perspex jar was used and the temperature difference was not getting higher than $35 \mathrm{~K}$. Here, a steel jar was used, so the frictional heat could be higher but probably not as much as needed for the monoclinic high-temperature guanidine hydroiodide phase. Another explanation would be the pressure, introduced by the milling balls. That would make less voluminous structures more preferable, which is the case for the guanidine hydroiodide phase transition. On the other hand, we could not observe the high-temperature phase while milling guanidine hydroiodide in the same conditions but without lead(II) iodide (see Figure S10).

The nucleation speed of the compounds $\mathbf{1}$ and $\mathbf{3}$, as inferred by their time of appearance, is rather similar, while $\mathbf{2}$ nucleates a little bit later. All three compounds get formed in every synthesis, although the amount of $\mathbf{1}$ is very low in the synthesis of $\mathbf{4}$, were the ratio of the starting materials was the less fitting (4:1). The growth speed of these three phases instead differs significantly. Phase $\mathbf{3}$ is formed in all four syntheses and always grows faster than $\mathbf{1}$ and $\mathbf{2}$. We consider this to be the reason why it is always present as an intermediate with a remarkable amount. The nucleation of $\mathbf{4}$ instead seems to be the least favored one. Beside its own synthesis compound $\mathbf{4}$ acts as an intermediate only in the synthesis of $\mathbf{3}$ and there it can be detected very late for the first time, after $15 \mathrm{~min}$. But then its growth is even faster than the one of 3, resulting in a decrease of the reaction speed. It just stops when no starting materials are left. Most likely after that time $\mathbf{3}$ is getting formed from the intermediates. The shrinking speed of an intermediate is following its own growth speed observed before. We believe this to be another hint that the different nucleation and growth speeds are strictly linked to the structures of the compounds. On one hand, considering only the inorganic moiety, compound $\mathbf{3}$ has a simple corner-connected chain structure. The growth of this perovskite chain, being 1D, is conceptually less demanding than the one of a 2D (and $\langle 110\rangle$-oriented) perovskite layer as in $\mathbf{2}$, or than the edge-sharing double chains of $\mathbf{1}$. For compound 4, instead, a certain amount of isolated $\left[\mathrm{PbI}_{6}\right]^{4-}$-octahedra needs to be formed before the crystal can nucleate. We consider this formation of non polymeric objects carrying a high charge to be slow and therefore the reason for the late nucleation. When a critical number is reached, the growth of the crystal just demands an arrangement of the single units, no further bond being needed. This could be the reason for the fast growth, once it is nucleated. On the other hand, it is the arrangement of the inorganic moieties, as complemented by the guanidinium-ions, that dictates all crystal structures. As mentioned, 
the N-I distances are getting shorter from 1 to $\mathbf{4}$, indicating a progressively stronger interaction between the two moieties. This suggests the organic cations are increasingly better templating the arrangement of the inorganic units. Therefore the crystal growth speed should increase from $\mathbf{1}$ to $\mathbf{4}$, once the nucleation has happened, as observed experimentally.

\section{Conclusions}

We have shown how mechanochemistry could be used for an easy and fast synthesis of hybrid organicinorganic materials of different dimensionality. In the studied case of guanidinium lead(II) iodides, the stoichiometric control, given by using different amounts of guanidine hydroiodide, dictates the final product up to the formation of isolated $\left[\mathrm{PbI}_{6}\right]^{4-}$-octahedra. High-temperature studies lead additionally to the observation of new phases. While some follow the simple symmetrization of the inorganic moiety, $\left(\mathrm{C}\left(\mathrm{NH}_{2}\right)_{3}\right) \mathrm{PbI}_{3} 1$ forms at $570 \mathrm{~K}$ a rare, open 3D framework. The syntheses were investigated by in situ powder X-ray diffraction. The results show that the four described guanidinium lead(II) iodides easily convert into each other during milling processes. The low barrier of these changes is also proven by the temperature study of compound $\mathbf{4}$, which decomposes into $\mathbf{3}$. This subtle equilibrium between the phases and additionally the formation of an unexpected high temperature phase make the whole milling process very complex. The compounds 1-4 show different and recurring behavior in nucleation, growth and intermediate formation. We have linked this to the complexity of the inorganic moiety and the strength of the present hydrogen bonds.

\section{Acknowledgement}

We thank Tomasz Poręba for the help with single crystal measurements and data analysis. The authors are grateful for the funding received from the European Union's Horizon 2020 research and innovation programme under the Marie Skłodowska-Curie grant agreement No 701647.

\section{Supporting information}

Supporting information available containing the Rietveld refinements for all structures, tables with selected bond length and angles, and powder patterns of the high-temperature investigations.

\section{References}

[1] P. Balaz, M. Achimovicova, M. Balaz, P. Billik, Z. Cherkezova-Zheleva, J. M. Criado, F. Delogu, E. Dutkova, E. Gaffet, F. J. Gotor, R. Kumar, I. Mitov, T. Rojac, M. Senna, A. Streletskii, and K. Wieczorek-Ciurowa. Hallmarks of mechanochemistry: From nanoparticles to technology. Chem. Soc. Rev., 42(18):7571-7637, 2013.

[2] T. Friscic. Supramolecular concepts and new techniques in mechanochemistry: Cocrystals, cages, rotaxanes, open metal-organic frameworks. Chem. Soc. Rev., 41(9):3493-3510, 2012.

[3] K. Tanaka and F. Toda. Solvent-free organic synthesis. Chem. Rev., 100(3):1025-1074, 2000.

[4] S. L. James, C. J. Adams, C. Bolm, D. Braga, P. Collier, T. Friscic, F. Grepioni, K. D. M. Harris, G. Hyett, W. Jones, A. Krebs, J. Mack, L. Maini, A. G. Orpen, I. P. Parkin, W. C. Shearouse, J. W. Steed, and D. C. Waddell. Mechanochemistry: Opportunities for new and cleaner synthesis. Chem. Soc. Rev., 41(1):413-447, 2012.

[5] D. Hasa and W. Jones. Screening for new pharmaceutical solid forms using mechanochemistry: A practical guide. Adv. Drug Delivery. Rev., 117:147-161, 2017. 
[6] E. Boldyreva. Mechanochemistry of inorganic and organic systems: What is similar, what is different? Chem. Soc. Rev., 42(18):7719-7738, 2013.

[7] D. Tan and T. Friscic. Mechanochemistry for organic chemists: An update. Eur. J. Org. Chem., 2018(1):18-33, 2018.

[8] V. V. Boldyrev and K. Tkacova. Mechanochemistry of solids: Past, present, and prospects. J. Mater. Synth. Process., 8(3-4):121-132, 2000.

[9] C. Suryanarayana. Mechanical alloying and milling. Prog. Mater Sci., 46(1-2):1-184, 2001.

[10] A. F. Fuentes and L. Takacs. Preparation of multicomponent oxides by mechanochemical methods. J. Mater. Sci., 48(2):598-611, 2013.

[11] T. Friscic, I. Halasz, P. J. Beldon, A. M. Belenguer, F. Adams, S. A. J. Kimber, V. Honkimaki, and R. E. Dinnebier. Real-time and in situ monitoring of mechanochemical milling reactions. Nat. Chem., 5(1):66-73, 2013.

[12] X. H. Ma, W. B. Yuan, S. E. J. Bell, and S. L. James. Better understanding of mechanochemical reactions: Raman monitoring reveals surprisingly simple 'pseudo-fluid' model for a ball milling reaction. Chem. Commun., 50(13):1585-1587, 2014.

[13] L. Batzdorf, F. Fischer, M. Wilke, K. J. Wenzel, and F. Emmerling. Direct in situ investigation of milling reactions using combined x-ray diffraction and raman spectroscopy. Angew. Chem., Int. Ed., 54(6):1799-1802, 2015.

[14] H. Kulla, M. Wilke, F. Fischer, M. Rollig, C. Maierhofer, and F. Emmerling. Warming up for mechanosynthesis - temperature development in ball mills during synthesis. Chem. Commun., 53(10):1664-1667, 2017.

[15] K. Užarević, I. Halasz, and T. Friščić. Real-time and in situ monitoring of mechanochemical reactions: A new playground for all chemists. J. Phys. Chem. Lett., pages 4129-4140, 2015.

[16] M. Wilke, L. Batzdorf, F. Fischer, K. Rademann, and F. Emmerling. Cadmium phenylphosphonates: preparation, characterisation and in situ investigation. RSC Adv., 6(42):36011-36019, 2016.

[17] M. Wilke, A. Kabelitz, A. Zimathies, K. Rademann, and F. Emmerling. Crystal structure and in situ investigation of a mechanochemical synthesized 3d zinc N-(phosphonomethyl)glycinate. J. Mater. Sci., 52(20):12013-12020, 2017.

[18] S. Lukin, T. Stolar, M. Tireli, V. Blanco Maria, D. Babić, T. Friščić, K. Užarević, and I. Halasz. Tandem in situ monitoring for quantitative assessment of mechanochemical reactions involving structurally unknown phases. Chem. - Eur. J., 23(56):13941-13949, 2017.

[19] D. Prochowicz, M. Franckevičius, A. M. Cieślak, S. M. Zakeeruddin, M. Grätzel, and J. Lewiński. Mechanosynthesis of the hybrid perovskite ch3nh3pbi3: characterization and the corresponding solar cell efficiency. J. Mater. Chem. A, 3(41):20772-20777, 2015.

[20] D. J. Kubicki, D. Prochowicz, A. Hofstetter, M. Saski, P. Yadav, D. Bi, N. Pellet, J. Lewiński, S. M. Zakeeruddin, M. Grätzel, and L. Emsley. Formation of stable mixed guanidinium-methylammonium phases with exceptionally long carrier lifetimes for high-efficiency lead iodide-based perovskite photovoltaics. J. Am. Chem. Soc., 140(9):3345-3351, 2018.

[21] D. Prochowicz, P. Yadav, M. Saliba, D. J. Kubicki, M. M. Tavakoli, S. M. Zakeeruddin, J. Lewiński, L. Emsley, and M. Grätzel. One-step mechanochemical incorporation of an insoluble cesium additive for high performance planar heterojunction solar cells. Nano Energy, 49:523-528, 2018. 
[22] P. Pal, S. Saha, A. Banik, A. Sarkar, and K. Biswas. All-solid-state mechanochemical synthesis and post-synthetic transformation of inorganic perovskite-type halides. Chem. - Eur. J., 24(8):1811$1815,2018$.

[23] P. P. Boix, K. Nonomura, N. Mathews, and S. G. Mhaisalkar. Current progress and future perspectives for organic/inorganic perovskite solar cells. Mater. Today, 17(1):16-23, 2014.

[24] M. A. Green, A. Ho-Baillie, and H. J. Snaith. The emergence of perovskite solar cells. Nat. Photonics, 8:506, 2014.

[25] B. Saparov and D. B. Mitzi. Organic-inorganic perovskites: Structural versatility for functional materials design. Chem. Rev., 116(7):4558-4596, 2016.

[26] C. O. Ramírez Quiroz, Y. Shen, M. Salvador, K. Forberich, N. Schrenker, G. D. Spyropoulos, T. Heumüller, B. Wilkinson, T. Kirchartz, E. Spiecker, P. J. Verlinden, X. Zhang, M. A. Green, A. Ho-Baillie, and C. J. Brabec. Balancing electrical and optical losses for efficient 4terminal Si-perovskite solar cells with solution processed percolation electrodes. J. Mater. Chem. A, 6(8):3583-3592, 2018.

[27] M. E. Kamminga, H.-H. Fang, M. R. Filip, F. Giustino, J. Baas, G. R. Blake, M. A. Loi, and T. T. M. Palstra. Confinement effects in low-dimensional lead iodide perovskite hybrids. Chem. Mater., 28(13):4554-4562, 2016.

[28] C. M. M. Soe, C. C. Stoumpos, M. Kepenekian, B. Traoré, H. Tsai, W. Nie, B. Wang, C. Katan, R. Seshadri, A. D. Mohite, J. Even, T. J. Marks, and M. G. Kanatzidis. New type of 2d perovskites with alternating cations in the interlayer space, $\left(\mathrm{C}\left(\mathrm{NH}_{2}\right)_{3}\right)\left(\mathrm{CH}_{3} \mathrm{NH}_{3}\right) \mathrm{nPbnI}_{3 n+1}$ : Structure, properties, and photovoltaic performance. J. Am. Chem. Soc., 139(45):16297-16309, 2017.

[29] J. L. Yan, W. M. Qiu, G. Wu, P. Heremans, and H. Z. Chen. Recent progress in 2d/quasi-2d layered metal halide perovskites for solar cells. J. Mater. Chem. A, 6(24):11063-11077, 2018.

[30] J. Guan, Z. Tang, and A. M. Guloy. $\alpha$ - $\left[\mathrm{NH}_{3}\left(\mathrm{CH}_{2}\right)_{5} \mathrm{NH}_{3}\right] \mathrm{SnI}_{4}$ : A new layered perovskite structure. Chem. Commun., (18):1833-1834, 1999.

[31] Zhang, Guo, G. Xu, M.-L. Fu, J.-P. Zou, and J.-S. Huang. $\left[\left(\mathrm{H}_{2} \mathrm{en}\right)_{7}\left(\mathrm{C}_{2} \mathrm{O}_{4}\right)_{2}\right] \mathrm{n}\left(\mathrm{Pb}_{4} \mathrm{I}_{18}\right)_{n} \cdot 4 \mathrm{nH}_{2} \mathrm{O}$, a new type of perovskite co-templated by both organic cations and anions. lnorg. Chem., 45(25):1002810030, 2006.

[32] N. Louvain and N. Mercier. A 3d metal halide framework in the organic-inorganic compound $\left(\mathrm{H}_{3} \mathrm{~N}\left(\mathrm{CH}_{2}\right)_{2} \mathrm{SS}\left(\mathrm{CH}_{2}\right)_{2} \mathrm{NH}_{3}\right)_{3} \mathrm{~Pb}_{5} \mathrm{I}_{16}$. Solid State Sci., 10(10):1269-1275, 2008.

[33] O. J. Weber, K. L. Marshall, L. M. Dyson, and M. T. Weller. Structural diversity in hybrid organic-inorganic lead iodide materials. Acta Crystallogr., Sect. B: Struct. Crystallogr. Cryst. Chem., 71(6):668-678, 2015.

[34] M. Daub, C. Haber, and H. Hillebrecht. Synthesis, crystal structures, optical properties, and phase transitions of the layered guanidinium-based hybrid perovskites $\left[\mathrm{C}\left(\mathrm{NH}_{2}\right)_{3}\right]_{2} \mathrm{MI}_{4} ; \mathrm{M}=\mathrm{Sn}, \mathrm{Pb}$. Eur. J. Inorg. Chem., 2017(7):1120-1126, 2017.

[35] V. Ban, Y. Sadikin, M. Lange, N. Tumanov, Y. Filinchuk, R. Černý, and N. Casati. Innovative in situ ball mill for x-ray diffraction. Anal. Chem., 89(24):13176-13181, 2017.

[36] P. R. Willmott, D. Meister, S. J. Leake, M. Lange, A. Bergamaschi, M. Böge, M. Calvi, C. Cancellieri, N. Casati, A. Cervellino, Q. Chen, C. David, U. Flechsig, F. Gozzo, B. Henrich, S. Jäggi-Spielmann, B. Jakob, I. Kalichava, P. Karvinen, J. Krempasky, A. Lüdeke, R. Lüscher, S. Maag, C. Quitmann, M. L. Reinle-Schmitt, T. Schmidt, B. Schmitt, A. Streun, I. Vartiainen, M. Vitins, X. Wang, and R. Wullschleger. The materials science beamline upgrade at the swiss light source. J. Synchrotron Radiat., 20(Pt 5):667-682, 2013. 
[37] C. Prescher and V. B. Prakapenka. DIOPTAS: A program for reduction of two-dimensional x-ray diffraction data and data exploration. High Pressure Res., 35(3):223-230, 2015.

[38] V. Dyadkin, P. Pattison, V. Dmitriev, and D. Chernyshov. A new multipurpose diffractometer PILATUS@SNBL. J. Synchrotron Radiat., 23(3):825-829, 2016.

[39] George Sheldrick. Crystal structure refinement with SHELXL. Acta Crystallogr., Sect. C: Struct. Chem., 71(1):3-8, 2015.

[40] A. Altomare, C. Cuocci, C. Giacovazzo, A. Moliterni, R. Rizzi, N. Corriero, and A. Falcicchio. EXPO2013: A kit of tools for phasing crystal structures from powder data. J. Appl. Crystallogr., 46:1231-1235, 2013.

[41] M. Grottel, M. Szafranski, and Z. Pajak. NMR study of cation motion in guanidinium iodoplumbates. Z. Naturforsch., A: Phys. Sci., 52(11):783-788, 1997.

[42] M. Szafrański. Investigation of phase instabilities in guanidinium halogenoplumbates(ii). Thermochim. Acta, 307(2):177-183, 1997.

[43] C. C. Stoumpos, L. Mao, C. D. Malliakas, and M. G. Kanatzidis. Structure-band gap relationships in hexagonal polytypes and low-dimensional structures of hybrid tin iodide perovskites. lnorg. Chem., 56(1):56-73, 2017.

[44] T. Baikie, Y. Fang, J. M. Kadro, M. Schreyer, F. Wei, S. G. Mhaisalkar, M. Graetzel, and T. J. White. Synthesis and crystal chemistry of the hybrid perovskite $\left(\mathrm{CH}_{3} \mathrm{NH}_{3}\right) \mathrm{PbI}_{3}$ for solid-state sensitised solar cell applications. J. Mater. Chem. A, 1(18):5628-5641, 2013.

[45] G. Kieslich, S. Sun, and A. K. Cheetham. An extended tolerance factor approach for organic-inorganic perovskites. Chem. Sci., 6(6):3430-3433, 2015.

[46] M. Szafranski and M. Jarek. Origin of spontaneous polarization and reconstructive phase transition in guanidinium iodide. CrystEngComm, 15(23):4617-4623, 2013.

[47] A. A. L. Michalchuk, I. A. Tumanov, V. A. Drebushchak, and E. V. Boldyreva. Advances in elucidating mechanochemical complexities via implementation of a simple organic system. Faraday Discuss., 170:311-335, 2014.

[48] A. A. L. Michalchuk, I. A. Tumanov, S. Konar, S. A. J. Kimber, C. R. Pulham, and E. V. Boldyreva. Challenges of mechanochemistry: Is in situ real-time quantitative phase analysis always reliable? a case study of organic salt formation. Adv. Sci., 4(9), 2017.

[49] A. A. L. Michalchuk, K. S. Hope, S. R. Kennedy, M. V. Blanco, E. V. Boldyreva, and C. R. Pulham. Ball-free mechanochemistry: in situ real-time monitoring of pharmaceutical co-crystal formation by resonant acoustic mixing. Chem. Commun., 54(32):4033-4036, 2018.

[50] H. Kulla, S. Haferkamp, I. Akhmetova, M. Röllig, C. Maierhofer, K. Rademann, and F Emmerling. In situ investigations of mechanochemical one-pot syntheses. Angew. Chem., Int. Ed., 57(20):5930$5933,2018$. 